\title{
Waist-to-height ratio, waist circumference, and body mass index as indices of cardiometabolic risk among 36,642 Taiwanese adults
}

\author{
Wen-Cheng Li • I-Chuan Chen $\cdot$ Yu-Che Chang • \\ Song-Seng Loke $\cdot$ Shih-Hao Wang $\cdot$ Kuang-Yu Hsiao
}

Received: 17 June 2011/ Accepted: 18 November 2011/Published online: 11 December 2011

(C) The Author(s) 2011. This article is published with open access at Springerlink.com

\begin{abstract}
Purpose We aimed to investigate the association of body mass index (BMI), waist circumference (WC), and waistto-height ratio (WHtR) with cardiometabolic risk.

Methods In this cross-sectional study, 21,038 men and 15,604 women who participated in a health check-up were included.

Results In both men and women, the area under the curve (AUC) of WHtR was significantly greater than that of BMI or WC in the prediction of diabetes, hypertension, high total cholesterol, high triglycerides, and low HDL-cholesterol $(P<0.05$ for all). The AUC for WHtR in the prediction of metabolic syndrome (MS) was also highest in the women $(P<0.05)$. After adjustment for potential
\end{abstract}

\section{W.-C. Li}

Department of Occupation Medicine, Chang-Gung Memorial Hospital, Keelung Branch, No. 222, Maijin Rd., Keelung 200, Taiwan

\section{W.-C. Li ( $\square)$}

Department of Occupation Medicine, Chang-Gung Memorial

Hospital, No. 5, Fu-Hsing Street, Guei-Shan, Taoyuan 333,

Taiwan, ROC

e-mail: 620313@adm.cgmh.org.tw

I.-C. Chen · K.-Y. Hsiao

Department of Emergency Medicine, Chang-Gung Memorial Hospital, Chiayi Branch, No. 6, West Sec. Chia-Pu Rd, Put-Zu, Chiayi 600, Taiwan

I.-C. Chen · K.-Y. Hsiao

Chang Gung Institute of Technology, Chiayi Branch, No. 2,

West Sec. Chia-Pu Rd, Put-Zu, Chiayi 600, Taiwan

\section{Y.-C. Chang}

Department of Emergency Medicine, Chang-Gung Memorial Hospital, Linkou Branch, No. 5, Fu-Hsing Street, Guei-Shan,

Taoyuan 333, Taiwan confounders, the odds ratios and $95 \%$ confidence intervals for MS for each standard deviation increase in BMI, WHtR, and WC were 1.47 (1.46-1.49), 1.32 (1.31-1.33), and 1.19 (1.18-1.19), respectively. Finally, patients of either sex with a normal BMI or WC level, but with an elevated WHtR, had higher levels of various cardiometabolic risk factors in comparison with their normal BMI or WC, but low WHtR, counterparts $(P<0.05$ for all).

Conclusion Among Taiwanese adults, a WHtR greater than 0.5 is a simple, yet effective indicator of centralized obesity and associated cardiometabolic risk, even among individuals deemed 'healthy' according to BMI and WC.

Keywords Waist-to-height ratio - Waist circumference Obesity $\cdot$ Diabetes $\cdot$ Body mass index $\cdot$ Asian

Y.-C. Chang

College of Medicine, Chang-Gung University, No. 259,

Wen-Hwa 1st Rd., Guei-Shan, Taoyuan 333, Taiwan

\section{S.-S. Loke}

Department of Family Medicine, Chang-Gung Memorial

Hospital, Kaohsiung Branch, No. 123, Dapi Rd., Niaosong

Township, Kaohsiung County 833, Taiwan

S.-H. Wang

Institute of Environmental and Occupational Health Science,

National Yang-Ming University, Taipei 112, Taiwan

\section{S.-H. Wang}

Department of Emergency Medicine, Mackay Memorial

Hospital, No. 92, Sec. 2, Zhongshan N. Rd., Zhongshan

Dist., Taipei 10449, Taiwan 


\section{Introduction}

Current estimates from the International Obesity Task Force suggest that at least 1.1 billion people across the globe are overweight and 312 million of them are obese [1]. It is now well established that obesity, as most commonly defined according to body mass index (BMI), substantially increases the risk of type-2 diabetes [2], hypertension [2], cardiovascular disease [3], and all-cause mortality [4]. However, it has become accepted that the location of excess adiposity is a strong determinant of cardiometabolic risk [5]. Specifically, the central deposition of excess weight has been proven to be a stronger predictor of risk of morbidity [6-10] and mortality [11] in comparison with overall obesity, as defined by BMI alone.

Although waist circumference (WC) is often advocated as a simple and accurate anthropometric marker of central obesity and associated cardiometabolic risk [12], and its use has been adopted into clinical screening guidelines [13], the measure is not without limitations. First, WC cutoff points cannot be used universally across gender or race [14]. Indeed, the optimal WC cutoffs for denoting cardiometabolic risk may even differ between Asians from different countries $[15,16]$. The application of WC to assess cardiometabolic risk also assumes, albeit erroneously, that risk stratification is not influenced by patient height. For example, it has recently been shown that the risk of metabolic syndrome within a given WC strata is significantly higher among shorter individuals [17].

The waist-to-height ratio (WHtR) is an alternative anthropometric index of central obesity that circumvents the limitations of WC [18]. First, due to the inclusion of height into the index, any potential confounding of cardiometabolic risk by height is avoided. Second, studies have found similar WHtR cutoffs for increased cardiometabolic risk among Caucasian [19] and Asian [20] populations as well as men and women [21]. In fact, a WHtR cutoff value of 0.5 has been proposed as an indicator of cardiometabolic risk for both Japanese [22], Korean [23], and British [19] men and women. Finally, WHtR has also been shown to denote cardiometabolic risk among individuals who are not obese according to other anthropometric indices [23-25].

Despite apparently low levels of obesity [26] relative to those reported in North America [27], the rates of diabetes [28] and metabolic syndrome [29] among Taiwanese are alarmingly high. Thus, there remains a need to elucidate proper anthropometric criteria to delineate Taiwanese individuals at the highest cardiometabolic risk. The aim of the current study was threefold: (1) to investigate the association of BMI, WC, and WHtR with diabetes mellitus, hypertension, dyslipidemia, and metabolic syndrome in a large sample of Taiwanese individuals; (2) to determine the cutoff points of BMI, WC, and WHtR predictive of cardiometabolic risk factors; and (3) to quantify cardiometabolic risk among those who have elevated WHtR, but normal BMI or WC.

\section{Subjects and methods}

\section{Subjects}

Data on 38,406 adult ( $\geq 18$ years) Taiwanese subjects who had health check-ups in 2010 were retrospectively collected from the health centers located in four separate branches of Chang-Gung Memorial Hospital, including the Keelung and Linkou branches of northern Taiwan and the Chiayi and Kaohsiung branches of southern Taiwan. Subjects with incomplete data, as well as those who were pregnant or had a chronic disease that may affect the metabolic status or body composition (e.g., thyroid or hypothalamic disease, chronic hepatitis, and cirrhosis), were excluded from analysis $(n=1,764)$. The sample used for the current analysis consisted of 21,038 men and 15,604 women.

\section{Collection of data}

All data collection was conducted during a single visit by full-time nurses at the health examination center who had received uniform training and adhered to the standard operating procedure (SOP). Nurses at each participating health center administered questionnaires regarding lifestyle (including smoking and drinking), medical history (including past illness history and medication history), and physiological conditions (including pregnancy and fasting time) to all subjects during their health check-up. The nurses verified the completion of each questionnaire prior to collection. During the same visit, blood pressure, height, weight, and waist circumstance were measured, and fasting blood samples were taken. All subject information was coded electronically and entered into a central subject record database. In order to ensure quality control, a monitor was employed by the investigational institution to review the data collection process through sampling with an SOP check list.

Anthropometric measurements

The height meter was calibrated daily using a one-meter standard bar from the Bureau of Standards, Metrology, and Inspection, Taiwan. Height was measured while subjects stood erect, barefoot, with feet together, looking forward. The weight scale was calibrated daily using two $20-\mathrm{kg}$ standard weights. Weight was measured by an automatic 
scale with subjects wearing light shirt and shorts or a skirt. BMI was then calculated as weight in $\mathrm{kg}$ divided by height in meters squared $\left(\mathrm{kg} / \mathrm{m}^{2}\right)$. Normal BMI level was classified as $18.5-23.9 \mathrm{~kg} / \mathrm{m}^{2}$, as per the guidelines set forth by the Taiwan Department of Health. WC was measured at the mid-level between the iliac crest and the lower border of the twelfth rib while the subject stood with feet $25-30 \mathrm{~cm}$ apart. A normal WC level in men and women was defined as $<90$ and $<80 \mathrm{~cm}$, respectively.

\section{Measurement of cardiometabolic risk factors}

After a 10-min rest, blood pressure (BP) was recorded with the subject in the seated position using an automated sphygmomanometer placed on the subject's right arm. BP was measured three times, and the lowest reading was recorded. Individuals were deemed hypertensive if they were taking antihypertensive medications, if they selfreported a diagnosis of hypertension, if their systolic pressure was above $140 \mathrm{~mm} \mathrm{Hg}$, if their diastolic pressure was above $90 \mathrm{~mm} \mathrm{Hg}$, or if a combination of these features was recorded [30]. Subjects fasted for a minimum of $12 \mathrm{~h}$ and avoided a high-fat diet and alcohol consumption for at least $24 \mathrm{~h}$ prior to phlebotomy. A fasting venous blood sample was obtained between 5:30 am and 11:00 am and stored in a $4{ }^{\circ} \mathrm{C}$ refrigerator prior to analysis in the hospital laboratory. Clinical chemistry workup included total cholesterol, HDL-C, TG, fasting plasma glucose (FPG), and uric acid. Blood tests were carried out by the College of American Pathologists (CAP)-accredited hospital laboratory in accordance with the laboratory SOP. Participants were considered to have diabetes if they reported current usage of antidiabetic medications, reported a previous diagnosis of diabetes or had an FPG glucose above $126 \mathrm{mg} / \mathrm{dl}$ [31]. In terms of lipid variables, the cutoff points were as follows: hypercholesterolemia (plasma TC $\geq 240 \mathrm{mg} / \mathrm{dl}$ and/or use of medications to lower blood cholesterol), hypertriglyceridemia ( $\mathrm{TG} \geq 200 \mathrm{mg} / \mathrm{dl}$ ), low HDL-C (HDL-C $<40 \mathrm{mg} / \mathrm{dl}$ in men and women), and high LDL-C (LDL-C $\geq 160 \mathrm{mg} / \mathrm{dl}$ and/or use of medications to lower blood cholesterol) [32].

A diagnosis of metabolic syndrome was defined as a subject presenting at least 3 of the 5 factors described by the Third Adult Treatment Panel (ATP III) of the National Cholesterol Education Program (NCEP) [33]. The diagnostic criteria were defined as follows: (1) high blood pressure (a systolic blood pressure $\geq 130 \mathrm{~mm} \mathrm{Hg}$ and/or diastolic pressure $\geq 85 \mathrm{~mm} \mathrm{Hg}$, under treatment, or already diagnosed with hypertension); (2) high serum triglyceride $(\geq 150 \mathrm{mg} / \mathrm{dl}$ or under treatment); (3) decreased HDL-C $(<40 \mathrm{mg} / \mathrm{dl}$ for males and $<50 \mathrm{mg} / \mathrm{dl}$ for females or under treatment); (4) hyperglycemia (FBG $\geq 100 \mathrm{mg} / \mathrm{dl}$, under treatment, or previously diagnosed with diabetes mellitus); and abdominal obesity. Waist circumference cutoffs were modified for Asian populations [2]. A waist circumference $\geq 90 \mathrm{~cm}$ for men and $\geq 80 \mathrm{~cm}$ for women plus the other two risk factors or the waist circumstance within the threshold plus the other three or more risk factors resulted in a diagnosis of metabolic syndrome.

\section{Statistical analyses}

Comparisons between men and women were made using independent samples $t$ tests for continuous data and chisquare tests for categorical data. Pearson's correlation coefficients were used to determine the correlation between anthropometric indices and cardiometabolic risk factors. A receiver operating characteristic (ROC) curve is a graphical plot of the true-positive rate (sensitivity) versus the falsepositive rate (100-specificity) for a binary variable across a range of thresholds. In the current study, the ROC curves were used to demonstrate the discriminatory ability of an anthropometric index (e.g., WC) over the entire range of possible values in the detection of a cardiometabolic outcome (i.e., diabetes) as quantified by the area under the curve (AUC). The optimal cutoff point for each anthropometric variable in the prediction of a given cardiometabolic outcome was established based on the highest combination of sensitivity and specificity. Odds ratios (ORs) were calculated using multiple logistic regression analysis and are presented with their 95\% confidence intervals (CIs). $P<0.05$ was considered to be statistically significant. The data were analyzed using SPSS version 12.0 for Windows (SPSS, Inc, Chicago, IL, USA). Pairwise comparison of ROC curves was made using MedCalc for Windows, version 9.38 (MedCalc Software, Mariakerke, Belgium).

\section{Results}

The basic characteristics and the prevalence of cardiometabolic risk factors of the 21,038 men and 15,604 women in the study sample are presented in Table 1 . The men and women in the sample were comparable in terms of mean age ( $37.2 \pm 9.4$ and $37.3 \pm 10.4$ years, respectively, $P=0.437)$, prevalence of diabetes $(1.3$ vs. $1.2 \%$, $P=0.477)$, and high total cholesterol (5.2 vs. 5.0\%, $P=0.467)$. However, there were significant differences between the men and women in all other assessed variables (all $P<0.001$ ). Specifically, men had a higher BMI $\left(24.8 \pm 3.5\right.$ vs. $\left.22.5 \pm 4.0 \mathrm{~kg} / \mathrm{m}^{2}\right)$, WC $(84.8 \pm 9.1$ vs. $73.3 \pm 9.4 \mathrm{~cm})$, and WHtR $(0.49 \pm 0.05$ vs. $0.46 \pm 0.06)$ in comparison with women. The prevalence of hypertension $(6.2 \%$ vs. $3.8 \%)$, smoking $(29.6 \%$ vs. $8.8 \%)$, alcohol consumption $(37.5 \%$ vs. $11.5 \%)$, high TG (13.3\% vs. 
Table 1 Characteristics of study population

\begin{tabular}{|c|c|c|c|}
\hline & Men $(n=21,038)$ & Women $(n=15,604)$ & $P$ value \\
\hline Age (years) ${ }^{\mathrm{a}}$ & $37.24 \pm 9.39$ & $37.33 \pm 10.35$ & 0.437 \\
\hline BMI $(\mathrm{kg} / \mathrm{m} 2)^{\mathrm{b}}$ & $24.82 \pm 3.54$ & $22.52 \pm 3.95$ & $<0.001^{*}$ \\
\hline $\mathrm{WC}(\mathrm{cm})^{\mathrm{a}}$ & $84.76 \pm 9.07$ & $73.26 \pm 9.36$ & $<0.001^{*}$ \\
\hline $\mathrm{WHtR}^{\mathrm{a}}$ & $0.494 \pm 0.053$ & $0.462 \pm 0.061$ & $<0.001^{*}$ \\
\hline $\mathrm{SBP}(\mathrm{mm} \mathrm{Hg})^{\mathrm{a}}$ & $126.67 \pm 13.87$ & $115.91 \pm 15.69$ & $<0.001 *$ \\
\hline $\mathrm{DBP}(\mathrm{mm} \mathrm{Hg})^{\mathrm{a}}$ & $78.90 \pm 10.14$ & $72.22 \pm 10.00$ & $<0.001^{*}$ \\
\hline FBG $(\mathrm{mg} / \mathrm{dl})^{\mathrm{a}}$ & $91.93 \pm 18.48$ & $90.27 \pm 18.68$ & $<0.001 *$ \\
\hline $\mathrm{TC}(\mathrm{mg} / \mathrm{dl})^{\mathrm{a}}$ & $184.18 \pm 33.01$ & $179.57 \pm 33.17$ & $<0.001^{*}$ \\
\hline $\mathrm{TG}(\mathrm{mg} / \mathrm{dl})^{\mathrm{a}}$ & $130.57 \pm 103.71$ & $86.01 \pm 58.12$ & $<0.001^{*}$ \\
\hline HDL-C (mg/dl $)^{\mathrm{a}}$ & $49.72 \pm 11.16$ & $61.29 \pm 13.34$ & $<0.001 *$ \\
\hline TC/HDL-C ratio ${ }^{a}$ & $3.87 \pm 1.08$ & $3.05 \pm 0.82$ & $<0.001^{*}$ \\
\hline Diabetes mellitus, $n(\%)^{\mathrm{b}}$ & $278(1.3)$ & $193(1.2)$ & 0.477 \\
\hline Hypertension, $n(\%)^{\mathrm{b}}$ & $1,311(6.2)$ & $594(3.8)$ & $<0.001 *$ \\
\hline High TC, $n(\%)^{\mathrm{b}}$ & $1,094(5.2)$ & $785(5.0)$ & 0.467 \\
\hline High TG, $n(\%)^{\mathrm{b}}$ & 2,797 (13.3) & $590(3.8)$ & $<0.001^{*}$ \\
\hline Low HDL-C, $n(\%)^{\mathrm{b}}$ & $3,530(16.8)$ & $532(3.4)$ & $<0.001 *$ \\
\hline Current drinker, $n(\%)^{\mathrm{b}}$ & $7,897(37.5)$ & $1,794(11.5)$ & $<0.001 *$ \\
\hline Current smoker, $n(\%)^{\mathrm{b}}$ & $6,230(29.6)$ & $1,377(8.8)$ & $<0.001 *$ \\
\hline
\end{tabular}

All numbers are means \pm standard deviation unless specified

$P$ values are from ${ }^{\mathrm{a}}$ independent two sample $t$ tests or ${ }^{\mathrm{b}}$ chi-square tests

$B M I$ body mass index, $W C$ waist circumference, $W H t R$ waist-to-height ratio, $F B G$ fasting blood glucose, $S B P$ systolic blood pressure, $D B P$ diastolic blood pressure, $T C$ total cholesterol, $T G$ triglycerides, $H D L-C$ high-density lipoprotein cholesterol

* Indicates significant difference between men and women, $P<0.05$

Table 2 Pearson's correlation coefficients between anthropometric indices and cardiometabolic risk factors in men and women

\begin{tabular}{|c|c|c|c|c|c|c|}
\hline & \multicolumn{2}{|l|}{ BMI } & \multicolumn{2}{|l|}{ WC } & \multicolumn{2}{|l|}{ WHtR } \\
\hline & Men & Women & Men & Women & Men & Women \\
\hline SBP & $0.367 *$ & $0.443 *$ & $0.359 *$ & $0.423 *$ & $0.363 *$ & $0.437 *$ \\
\hline DBP & $0.345^{*}$ & $0.379^{*}$ & $0.333^{*}$ & $0.348 *$ & $0.343 *$ & $0.348 *$ \\
\hline FBG & $0.159 *$ & $0.260 *$ & $0.181 *$ & $0.286^{*}$ & $0.205^{*}$ & $0.296^{*}$ \\
\hline TC & $0.188^{*}$ & $0.193 *$ & $0.204^{*}$ & $0.201 *$ & $0.237 *$ & $0.233^{*}$ \\
\hline TG & $0.263^{*}$ & $0.362 *$ & $0.275^{*}$ & $0.382 *$ & $0.293^{*}$ & $0.402 *$ \\
\hline HDL-C & $-0.329 *$ & $-0.346^{*}$ & $-0.330 *$ & $-0.344^{*}$ & $-0.325^{*}$ & $-0.339 *$ \\
\hline Uric acid & $0.330 *$ & $0.406 *$ & $0.306 *$ & $0.381^{*}$ & $0.289^{*}$ & $0.383^{*}$ \\
\hline
\end{tabular}

Data are correlation coefficients

$B M I$ body mass index, $W C$ waist circumference, $W H t R$ waist-to-height ratio, $F B G$ fasting blood glucose, $S B P$ systolic blood pressure, $D B P$ diastolic blood pressure, $T C$ total cholesterol, $T G$ triglycerides, $H D L-C$ high-density lipoprotein cholesterol

$* P<0.05$

$3.8 \%)$, and low HDL-C (16.8\% vs. $3.4 \%)$ was also higher in the men than in the women, respectively.

The correlations between anthropometric indices and cardiometabolic risk factors are shown in Table 2. In both men and women, BMI, WC, and WHtR were all significantly correlated with each cardiometabolic risk factor $(P<0.05)$. In comparison with BMI and WC, the WHtR was a stronger correlate of FBG, TC, and TG in both men and women.

The AUCs of the three anthropometric indices in the prediction of cardiometabolic risk factors are shown in Table 3. In both sexes, the AUC of WHtR was significantly higher than that of BMI or WC in the prediction of diabetes mellitus, hypertension, high TC, high TG, and low HDL-C 
Table 3 AUC for various anthropometric indices and cardiometabolic risk factors in men and women

\begin{tabular}{llll}
\hline Risk factor & BMI & WC & WHtR \\
\hline Men $(n=21,038)$ & & & \\
$\quad$ Diabetes mellitus & $0.624(0.592,0.656)$ & $0.689(0.683,0.695)$ & $0.741(0.735,0.747)^{*}$ \\
Hypertension & $0.593(0.586,0.600)$ & $0.704(0.698,0.710)$ & $0.735(0.729,0.741)^{*}$ \\
Metabolic syndrome & $0.839(0.833,0.846)$ & $0.861(0.855,0.867)^{*}$ & $0.858(0.852,0.864)$ \\
High TC & $0.619(0.603,0.635)$ & $0.629(0.613,0.644)$ & $0.652(0.637,0.667)^{*}$ \\
High TG & $0.705(0.659,0.714)$ & $0.705(0.696,0.714)$ & $0.720(0.711,0.729)^{*}$ \\
Low HDL-C & $0.509(0.502,0.512)$ & $0.678(0.668,0.687)$ & $0.680(0.671,0.689)^{*}$ \\
Women $(n=15,604)$ & $0.771(0.764,0.778)$ & $0.827(0.821,0.833)$ & $0.845(0.840,0.851)^{*}$ \\
Diabetes mellitus & $0.797(0.791,0.804)$ & $0.814(0.807,0.820)$ & $0.835(0.829,0.841)^{*}$ \\
Hypertension & $0.897(0.890,0.905)$ & $0.915(0.908,0.921)$ & $0.920(0.914,0.926)^{*}$ \\
Metabolic syndrome & $0.657(0.638,0.676)$ & $0.660(0.641,0.680)$ & $0.684(0.665,0.702)^{*}$ \\
High TC & $0.784(0.768,0.801)$ & $0.798(0.782,0.814)$ & $0.818(0.803,0.832)^{*}$ \\
High TG & $0.765(0.746,0.785)$ & $0.761(0.742,0.780)$ & $0.763(0.745,0.782)$ \\
Low HDL-C & & &
\end{tabular}

Data are AUC (95\% confidence interval)

$B M I$ body mass index, $W C$ waist circumference, $W H t R$ waist-to-height ratio, $F B G$ fasting blood glucose, $S B P$ systolic blood pressure, $D B P$ diastolic blood pressure, $T C$ total cholesterol, $T G$ triglycerides, $H D L-C$ high-density lipoprotein cholesterol

* AUC is significantly larger than the next smaller AUC; significance was calculated only for the difference between parameters with the highest and second highest AUC, $P<0.05$

Table 4 Cutoff points for anthropometric indices predictive of cardiometabolic risk factors

\begin{tabular}{|c|c|c|c|c|c|c|c|c|c|}
\hline \multirow[t]{2}{*}{ Risk factor } & \multicolumn{3}{|l|}{ BMI } & \multicolumn{3}{|l|}{ WC } & \multicolumn{3}{|l|}{ WHtR } \\
\hline & Cutoff & $\begin{array}{l}\text { Sensitivity } \\
(\%)\end{array}$ & $\begin{array}{l}\text { Specificity } \\
(\%)\end{array}$ & Cutoff & $\begin{array}{l}\text { Sensitivity } \\
(\%)\end{array}$ & $\begin{array}{l}\text { Specificity } \\
(\%)\end{array}$ & Cutoff & $\begin{array}{l}\text { Sensitivity } \\
(\%)\end{array}$ & $\begin{array}{l}\text { Specificity } \\
(\%)\end{array}$ \\
\hline \multicolumn{10}{|l|}{$\operatorname{Men}(n=21,038)$} \\
\hline Diabetes mellitus & 25.28 & 60.4 & 59.8 & 86.95 & 68.3 & 61.3 & 0.503 & 78.1 & 59.7 \\
\hline Hypertension & 25.74 & 62.4 & 66.7 & 87.90 & 64.0 & 67.03 & 0.509 & 69.1 & 65.8 \\
\hline Metabolic syndrome & 25.34 & 83.1 & 69.5 & 89.35 & 78.4 & 83.3 & 0.514 & 80.1 & 77.4 \\
\hline High TC & 24.53 & 66.2 & 51.7 & 83.65 & 72.6 & 78.0 & 0.482 & 79.1 & 44.2 \\
\hline High TG & 24.65 & 75.1 & 65.4 & 85.95 & 70.8 & 60.5 & 0.496 & 75.5 & 58.2 \\
\hline Low HDL-C & 24.74 & 69.7 & 58.1 & 85.95 & 65.6 & 60.8 & 0.496 & 69.0 & 58.3 \\
\hline \multicolumn{10}{|l|}{ Women $(n=15,604)$} \\
\hline Diabetes mellitus & 23.91 & 72.0 & 72.4 & 80.40 & 70.5 & 81.5 & 0.497 & 80.3 & 76.3 \\
\hline Hypertension & 23.46 & 77.9 & 69.8 & 76.40 & 80.5 & 71.3 & 0.485 & 81.8 & 72.3 \\
\hline Metabolic syndrome & 23.95 & 87.4 & 78.5 & 73.45 & 88.0 & 85.5 & 0.497 & 89.2 & 82.7 \\
\hline High TC & 22.59 & 64.2 & 61.3 & 75.70 & 57.2 & 67.6 & 0.470 & 65.4 & 63.5 \\
\hline High TG & 22.76 & 82.2 & 63.4 & 76.95 & 75.9 & 71.6 & 0.484 & 78.6 & 71.5 \\
\hline Low HDL-C & 23.10 & 74.8 & 66.2 & 75.70 & 71.6 & 67.7 & 0.467 & 79.5 & 61.5 \\
\hline
\end{tabular}

$B M I$ body mass index, $W C$ waist circumference, $W H t R$ waist-to-height ratio, $F B G$ fasting blood glucose, $S B P$ systolic blood pressure, $D B P$ diastolic blood pressure, $T C$ total cholesterol, $T G$ triglycerides, $H D L-C$ high-density lipoprotein cholesterol

$(P<0.05$ for all). Additionally, the AUC for the prediction of MS was highest for WHtR in the women (AUC $=0.920$ ), but for WC in the men (AUC $=0.861$ ).

Table 4 summarizes the optimal cutoff points of the three anthropometric indices in the prediction of cardiometabolic risk factors using ROC analysis. Among men, the optimal BMI cutoff values for predicting diabetes mellitus, hypertension, MS, and dyslipidemia varied from 24.5 to $25.7 \mathrm{~kg} / \mathrm{m}^{2}$; meanwhile, the optimal WC cutoff values varied from 83.7 to $89.4 \mathrm{~cm}$, and the optimal WHtR 
values varied from 0.48 to 0.51 . Among women, the BMI cutoff values for predicting cardiometabolic risk varied between 22.6 and $24.0 \mathrm{~kg} / \mathrm{m}^{2}$, while those for $\mathrm{WC}$ and WHtR varied between 73.5 and $80.4 \mathrm{~cm}$, and 0.47 and 0.50 , respectively.

In order to compare the relative strengths of the association of BMI, WC, and WHtR with MS, we calculated the ORs $(95 \% \mathrm{CI})$ of MS for each $1 \mathrm{SD}$ increase in the anthropometric indicators. The global goodness of fit of the models was assessed using the Bayesian Information Criterion (BIC). After adjustment for age, gender, tobacco, and alcohol consumption, the OR (95\% CI) for MS was higher for BMI (1.473 [1.457-1.489]) than for WHtR (1.320 [1.310-1.330]) or WC (1.188 [1.182-1.194]). The corresponding BIC values were the lowest for WHtR and highest for BMI (data not shown).

The normal weight subjects $(n=18,186)$ constituted $49.6 \%$ of the total population. Of the 8,594 normal weight men, $233(2.7 \%)$ had central obesity as defined by a WHtR $\geq 0.514$. As outlined in Table 5, the centrally obese, normal weight men were older and had greater levels of SBP, DBP, FBG, TC, TG, TC/HDL-C ratio, and uric acid in comparison with their normal weight and noncentrally obese counterparts. Of the 9,592 normal weight women, $600(6.3 \%)$ had central obesity (WHtR $\geq 0.497)$. The centrally obese, normal weight women were older and had greater levels of SBP, DBP, FBG, TC, TG, TC/HDL-C ratio, and uric acid in comparison with normal weight and non-centrally obese women.

The normal WC subjects $(n=27,469)$ constituted $47.7 \%$ of the total population. Of the 15,261 normal WC men, 1,699 (11.1\%) had central obesity as defined by a
WHtR $\geq 0.514$; meanwhile, of the 12,208 normal WC women, $678(5.6 \%)$ had central obesity (WHtR $\geq 0.497)$. Similar to the results reported among normal weight subjects, the centrally obese but normal WC men and women were older and had greater levels of SBP, DBP, FBG, TC, TG, TC/HDL-C ratio, and uric acid in contrast to noncentrally obese and normal WC counterparts (Table 6).

\section{Discussion}

Using a BMI cutoff of $\geq 27.0 \mathrm{~kg} / \mathrm{m}^{2}$, estimates suggest that the prevalence of obesity in Taiwanese men and women is 10.5 and $13.2 \%$, respectively [26]. In contrast, rates of obesity (BMI $\geq 30.0 \mathrm{~kg} / \mathrm{m}^{2}$ ) in the United States are approximately three times as high (32.2 and 35.5\% in men and women, respectively) [27]. Despite the threefold difference in obesity prevalence, rates of diabetes in Taiwan and United States are nearly identical (9.2\% [28] and 7.9\% [2], respectively), and rates of metabolic syndrome in Taiwan are not far behind those in the United States (15.7\% [29] and 23.7\% [34], respectively). Thus, even when applying Asian-specific thresholds, BMI appears to be a relatively poor predictor of cardiometabolic risk among Taiwanese adults. The findings of this study, which include data from over 36,000 men and women, suggest that a simple measure of centralized obesity (WHtR) may be a superior measure of cardiometabolic risk among Taiwanese. Additionally, WHtR may identify cardiometabolic risk even among individuals deemed 'healthy' according to more established indices (BMI and WC).

Table 5 Demographic and cardiometabolic risk factors in normal weight (body mass index $18.5-23.9 \mathrm{~kg} / \mathrm{m}^{2}$ ) adults by $\mathrm{WHtR}$

\begin{tabular}{|c|c|c|c|c|c|c|}
\hline & \multicolumn{3}{|l|}{$\begin{array}{l}\text { Men }(n=8,594) \\
\text { Waist-to-height ratio }\end{array}$} & \multicolumn{3}{|l|}{$\begin{array}{l}\text { Women }(n=9,592) \\
\text { Waist-to-height ratio }\end{array}$} \\
\hline & $<0.514(n=8,361)$ & $\geq 0.514(n=233)$ & $P$ value & $<0.497(n=8,992)$ & $\geq 0.497(n=600)$ & $P$ value \\
\hline Age (years) & $35.74 \pm 8.73$ & $50.92 \pm 14.49$ & $<0.001^{*}$ & $35.96 \pm 8.74$ & $44.45 \pm 13.83$ & $<0.001 *$ \\
\hline SBP (mm Hg) & $122.26 \pm 12.17$ & $129.89 \pm 15.05$ & $<0.001 *$ & $112.30 \pm 12.98$ & $120.11 \pm 18.40$ & $<0.001^{*}$ \\
\hline DBP (mm Hg) & $75.84 \pm 8.77$ & $80.28 \pm 10.87$ & $<0.001 *$ & $70.27 \pm 8.81$ & $72.99 \pm 10.31$ & $<0.001^{*}$ \\
\hline FBG (mg/dl) & $89.08 \pm 14.03$ & $99.07 \pm 26.61$ & $<0.001^{*}$ & $84.62 \pm 12.59$ & $92.83 \pm 19.08$ & $<0.001 *$ \\
\hline $\mathrm{TC}(\mathrm{mg} / \mathrm{dl})$ & $177.73 \pm 31.09$ & $193.92 \pm 37.01$ & $<0.001^{*}$ & $176.41 \pm 31.15$ & $186.73 \pm 37.14$ & $<0.001 *$ \\
\hline TG (mg/dl) & $102.81 \pm 74.84$ & $149.02 \pm 119.81$ & $<0.001^{*}$ & $74.23 \pm 40.84$ & $105.52 \pm 76.79$ & $<0.001 *$ \\
\hline HDL-C (mg/dl) & $53.24 \pm 11.34$ & $49.52 \pm 10.88$ & $<0.001^{*}$ & $63.64 \pm 12.93$ & $58.13 \pm 12.76$ & $<0.001^{*}$ \\
\hline TC/HDL-C ratio & $3.47 \pm 0.89$ & $4.07 \pm 1.09$ & $<0.001 *$ & $2.85 \pm 0.66$ & $3.33 \pm 0.87$ & $<0.001^{*}$ \\
\hline Uric acid & $6.25 \pm 1.15$ & $6.53 \pm 1.32$ & $0.002 *$ & $4.51 \pm 0.90$ & $4.91 \pm 1.16$ & $<0.001 *$ \\
\hline
\end{tabular}

Values are means $\pm \mathrm{SD}$, and $P$ values are from independent two sample $t$ tests

$F B G$ fasting blood glucose, $S B P$ systolic blood pressure, $D B P$ diastolic blood pressure, $T C$ total cholesterol, $T G$ triglycerides, $H D L-C$ highdensity lipoprotein cholesterol

* Indicates significant difference between men and women, $P<0.05$ 
Table 6 Demographic and cardiometabolic risk factors in normal waist circumference (men $<90 \mathrm{~cm}$, women $<80 \mathrm{~cm})$ adults by WHtR

\begin{tabular}{|c|c|c|c|c|c|c|}
\hline & \multicolumn{3}{|l|}{$\begin{array}{l}\text { Men }(n=15,261) \\
\text { Waist-to-height ratio }\end{array}$} & \multicolumn{3}{|l|}{$\begin{array}{l}\text { Women }(n=12,208) \\
\text { Waist-to-height ratio }\end{array}$} \\
\hline & $<0.514(n=13,562)$ & $\geq 0.514(n=1,699)$ & $P$ value & $<0.497(n=11,530)$ & $\geq 0.497(n=678)$ & $P$ value \\
\hline Age (years) & $35.87 \pm 8.42$ & $43.02 \pm 11.35$ & $<0.001 *$ & $35.57 \pm 8.79$ & $44.33 \pm 12.81$ & $<0.001 *$ \\
\hline $\mathrm{SBP}(\mathrm{mm} \mathrm{Hg})$ & $123.59 \pm 12.49$ & $129.39 \pm 14.03$ & $<0.001 *$ & $112.32 \pm 13.14$ & $122.83 \pm 18.76$ & $<0.001^{*}$ \\
\hline DBP (mm Hg) & $76.78 \pm 9.09$ & $80.89 \pm 10.15$ & $<0.001 *$ & $70.39 \pm 8.93$ & $74.93 \pm 10.66$ & $<0.001 *$ \\
\hline FBG (mg/dl) & $89.68 \pm 14.31$ & $95.55 \pm 21.88$ & $<0.001^{*}$ & $87.47 \pm 11.91$ & $94.09 \pm 21.37$ & $<0.001 *$ \\
\hline TC (mg/dl) & $179.92 \pm 31.56$ & $193.99 \pm 35.16$ & $<0.001^{*}$ & $175.83 \pm 31.17$ & $188.24 \pm 35.63$ & $<0.001 *$ \\
\hline TG (mg/dl) & $111.60 \pm 83.77$ & $159.34 \pm 132.43$ & $<0.001 *$ & $73.78 \pm 40.05$ & $113.64 \pm 88.51$ & $<0.001^{*}$ \\
\hline HDL-C (mg/dl) & $51.82 \pm 11.28$ & $47.80 \pm 10.86$ & $<0.001 *$ & $63.60 \pm 12.94$ & $57.09 \pm 11.98$ & $<0.001 *$ \\
\hline TC/HDL-C ratio & $3.61 \pm 0.95$ & $4.22 \pm 1.17$ & $<0.001^{*}$ & $2.85 \pm 0.67$ & $3.41 \pm 0.85$ & $<0.001 *$ \\
\hline Uric acid & $6.39 \pm 1.19$ & $6.71 \pm 1.28$ & $<0.001 *$ & $4.51 \pm 0.91$ & $5.06 \pm 1.12$ & $<0.001^{*}$ \\
\hline
\end{tabular}

Values are means $\pm \mathrm{SD}$, and $P$ values are from independent two sample $t$ tests

$F B G$ fasting blood glucose, $S B P$ systolic blood pressure, $D B P$ diastolic blood pressure, $T C$ total cholesterol, $T G$ triglycerides, $H D L-C$ highdensity lipoprotein cholesterol

* Indicates significant difference between men and women, $P<0.05$

It is generally accepted that obesity, as defined by BMI, increases the risk of type-2 diabetes [2], hypertension [2], cardiovascular disease [3], and all-cause mortality [4]. Unfortunately, the appropriate cutoff points to best identify at-risk individuals are not consistent across different populations. Although a number of authors and groups have proposed alternative BMI criteria specific to Asian populations [35, 36], there currently exists no consensus [37]. In fact, the most recent attempt on behalf of the World Health Organization (WHO) concluded that since the BMI cutoffs at which significant cardiometabolic risk begins varies between 26.0 and $31.0 \mathrm{~kg} / \mathrm{m}^{2}$, depending on country, no attempt was made to redefine cutoff points for Asian populations [37]. Unfortunately, in terms of tracking population obesity level and accurately identifying individuals at cardiometabolic risk, such matters are not trivial. For example, the prevalence of obesity in Taiwan is $10.5 \%$ in men and $13.2 \%$ in women when using the BMI cutoffs of $\geq 27.0 \mathrm{~kg} / \mathrm{m}^{2}$, but 2.4 and $5.6 \%$, respectively, when applying the BMI $\geq 30.0 \mathrm{~kg} / \mathrm{m}^{2}$ cutoffs [26]. The results of our ROC analysis suggest that the ideal BMI cutoffs for identifying cardiometabolic risk in Taiwanese men and women are $24.5-25.7 \mathrm{~kg} / \mathrm{m}^{2}$ and 22.6 and $24.0 \mathrm{~kg} / \mathrm{m}^{2}$, respectively.

Nevertheless, the central deposition of excess weight has been proven to be a stronger predictor of risk of morbidity [6-10] and mortality [11] in comparison with overall obesity. Although WC is often used as a marker of central obesity, and its use has been adopted into clinical screening guidelines [13], WC cutoff points cannot be used universally across gender or race [14]. Indeed, optimal WC cutoffs for denoting cardiometabolic risk may not only differ between Asians and Caucasians [14], but also between
Asians from different countries $[15,16]$. It is suggested that optimal WC cutoffs for abdominal obesity among men and women in Japan are 85 and $90 \mathrm{~cm}$ [38], respectively, while those in Korea are 90 and $85 \mathrm{~cm}$ [39]. By comparison, the results of the current study illustrate that the optimal WC cutoffs for predicting cardiometabolic risk among Taiwanese are between 83.7 and $89.4 \mathrm{~cm}$ in men and between 73.5 and $80.4 \mathrm{~cm}$ in women. In unison, these results highlight the variability in WC thresholds between race, gender, and even country of origin. Finally, the measurement of WC also ignores the reported influence of height on cardiometabolic risk $[17,40]$.

The WHtR is an alternative anthropometric index of central obesity that circumvents the limitations of WC by adjusting for variations in height and providing a universal cutoff value equally appropriate for use among Asian and Caucasian, as well as men and women [18, 19, 21-23, 41]. Specifically, Ashwell and Hsieh [18] have recently suggested that a WHtR threshold of 0.5 is appropriate to delineate patients with significant cardiometabolic risk from those without, regardless of sex and race. Our results in Taiwanese adults corroborate these suggestions, finding that the optimal threshold for identifying cardiometabolic risk was between 0.48 and 0.51 in the men and 0.47 and 0.50 in the women. Thus, a major advantage of WHtR over WC appears to be simplicity. Such an advantage could translate to enhanced delivery of public health messages aimed at reducing obesity rates, as well as the clinical screening of individuals at risk of cardiometabolic complications. To that end, Ashwell and Hsieh [18] suggest the following message: "Keep your waist circumference to less than half your height." 
Some authors suggest that WHtR may be the best simple anthropometric index for predicting a wide range of cardiometabolic risk factors associated with central obesity [18, 21, 41]. The results of our ROC analyses illustrated that in both sexes, the WHtR was superior to BMI and WC as a predictor of diabetes mellitus, hypertension, high TC, high TG, and low HDL-C. Additionally, in the women, the WHtR was also the best predictor of MS. Nevertheless, the results of logistic regression analysis, which investigated the relationship between a 1 SD increase in any of the three indices and the risk of MS, suggested that an increase in BMI had a slightly greater impact on MS risk in comparison with WHtR and WC. Thus, for optimal assessment of a patient's cardiometabolic risk, it may be ideal to use BMI in concert with a measure of central adiposity such as WC and WHtR, as has been previously suggested in clinical guidelines [13]. In prior studies, WHtR has also been shown to denote cardiometabolic risk among individuals who are not obese according to other anthropometric indices [23-25]. In agreement with these prior observations, the current study found that an elevated WHtR was able to predict elevated cardiometabolic risk in both men and women who had a normal BMI or WC level. Thus, WHtR may also be able to identify cardiometabolic risk among individuals deemed 'healthy' according to BMI and WC.

A number of limitations are inherent to the current study and warrant mention. First, since the study is cross-sectional in nature, future longitudinal studies assessing the prospective risk of cardiovascular disease and related mortality according to each anthropometric index are needed to fully elucidate the reported relationships. Although diet and physical activity are known confounders of the relationship between anthropometry and cardiometabolic risk, due to a lack of relevant data, these variables were not accounted for in the analysis. While we did not quantify the extent of the intra- and inter-observer error in the measurement of the various anthropometric outcomes, we took a number of precautions to ensure quality control in the collection of data (as described in the "Methods" sect.). Finally, we were also unable to examine the potential mechanisms behind the relationship between anthropometric markers and cardiometabolic risk factors. Nevertheless, the notable strength of the current study included data from over 36,000 men and women from both southern and northern parts of Taiwan as well as rigorous and comprehensive statistical analyses.

In conclusion, WHtR is a simple and effective index of cardiometabolic risk among Taiwanese men and women, which may be superior to BMI and WC. Indeed, a WHtR of $>0.5$ was shown to clearly identify men and women at an elevated risk of diabetes, hypertension, metabolic syndrome, and dyslipidemia. Our findings also highlight the variability in optimal cutoff points for established anthropometric indices of risk, such as BMI and WC, and reconfirm the notion that these values are lower in Asian versus Caucasian populations. Finally, our analyses revealed that WHtR can identify adults at cardiometabolic risk, even when such individuals are categorized as 'healthy' or 'normal' according to BMI or WC.

Acknowledgments We thank the staff of the Health Examination Centers in the Keelung, Linkou, Chiayi, and Kaohsiung branches of Cheng Gung Memorial Hospital for assistance with data collection.

Funding This research received no specific grant from any funding agency in the public, commercial, or not-for-profit sectors.

Conflict of interest The authors have nothing to declare.

Open Access This article is distributed under the terms of the Creative Commons Attribution Noncommercial License which permits any noncommercial use, distribution, and reproduction in any medium, provided the original author(s) and source are credited.

\section{References}

1. James PT, Rigby N, Leach R (2004) The obesity epidemic, metabolic syndrome and future prevention strategies. Eur J Cardiovasc Prev Rehabil 11:3-8

2. Mokdad AH, Ford ES, Bowman BA et al (2003) Prevalence of obesity, diabetes, and obesity-related health risk factors, 2001. JAMA 289:76-79

3. Hubert HB, Feinleib M, McNamara PM, Castelli WP (1983) Obesity as an independent risk factor for cardiovascular disease: a 26-year follow-up of participants in the Framingham Heart Study. Circulation 67:968-977

4. Calle EE, Thun MJ, Petrelli JM, Rodriguez C, Heath CW Jr (1999) Body-mass index and mortality in a prospective cohort of U.S. adults. N Engl J Med 341:1097-1105

5. Despres JP (2006) Abdominal obesity: the most prevalent cause of the metabolic syndrome and related cardiometabolic risk. Eur Heart J Suppl 8:B4-B12

6. Yusuf S, Hawken S, Ounpuu S et al (2005) Obesity and the risk of myocardial infarction in 27,000 participants from 52 countries: a case-control study. Lancet 366:1640-1649

7. Rexrode KM, Carey VJ, Hennekens CH et al (1998) Abdominal adiposity and coronary heart disease in women. JAMA 280:1843-1848

8. Wang Y, Rimm EB, Stampfer MJ, Willett WC, Hu FB (2005) Comparison of abdominal adiposity and overall obesity in predicting risk of type 2 diabetes among men. Am J Clin Nutr 81:555-563

9. Janssen I, Katzmarzyk PT, Ross R (2004) Waist circumference and not body mass index explains obesity-related health risk. Am J Clin Nutr 79:379-384

10. Balkau B, Deanfield JE, Despres JP et al (2007) International Day for the Evaluation of Abdominal Obesity (IDEA): a study of waist circumference, cardiovascular disease, and diabetes mellitus in 168,000 primary care patients in 63 countries. Circulation 116:1942-1951

11. Bigaard J, Tjonneland A, Thomsen BL, Overvad K, Heitmann BL, Sorensen TI (2003) Waist circumference, BMI, smoking, and mortality in middle-aged men and women. Obes Res 11:895-903 
12. Pouliot MC, Despres JP, Lemieux S et al (1994) Waist circumference and abdominal sagittal diameter: best simple anthropometric indexes of abdominal visceral adipose tissue accumulation and related cardiovascular risk in men and women. Am J Cardiol 73:460-468

13. National Institutes of health (1998) Clinical guidelines on the identification, evaluation, and treatment of overweight and obesity in adults- the evidence report. Obes Res 6(Suppl 2):51S209S

14. Misra A, Wasir JS, Vikram NK (2005) Waist circumference criteria for the diagnosis of abdominal obesity are not applicable uniformly to all populations and ethnic groups. Nutrition 21:969-976

15. Bei-Fan Z (2002) Predictive values of body mass index and waist circumference for risk factors of certain related diseases in Chinese adults: study on optimal cut-off points of body mass index and waist circumference in Chinese adults. Asia Pac J Clin Nutr 11(Suppl 8):S685-S693

16. Lin WY, Lee LT, Chen CY et al (2002) Optimal cut-off values for obesity: using simple anthropometric indices to predict cardiovascular risk factors in Taiwan. Int J Obes Relat Metab Disord 26:1232-1238

17. Schneider HJ, Klotsche J, Silber S, Stalla GK, Wittchen HU (2011) Measuring abdominal obesity: effects of height on distribution of cardiometabolic risk factors risk using waist circumference, waist-to-height ratio. Diabetes Care 34:e7

18. Ashwell M, Hsieh SD (2005) Six reasons why the waist-to-height ratio is a rapid and effective global indicator for health risks of obesity and how its use could simplify the international public health message on obesity. Int J Food Sci Nutr 56:303-307

19. Ashwell M, Lejeune S, McPherson K (1996) Ratio of waist circumference to height may be better indicator of need for weight management. BMJ 312:377

20. Hsieh SD, Yoshinaga H (1995) Abdominal fat distribution and coronary heart disease risk factors in men-waist/height ratio as a simple and useful predictor. Int $\mathrm{J}$ Obes Relat Metab Disord 19:585-589

21. Ho SY, Lam TH, Janus ED (2003) Waist to stature ratio is more strongly associated with cardiovascular risk factors than other simple anthropometric indices. Ann Epidemiol 13:683-691

22. Hsieh SD, Yoshinaga H, Muto T (2003) Waist-to-height ratio, a simple and practical index for assessing central fat distribution and metabolic risk in Japanese men and women. Int J Obes Relat Metab Disord 27:610-616

23. Park SH, Choi SJ, Lee KS, Park HY (2009) Waist circumference and waist-to-height ratio as predictors of cardiovascular disease risk in Korean adults. Circ J 73:1643-1650

24. Hsieh SD, Yoshinaga H, Muto T, Sakurai Y, Kosaka K (2000) Health risks among Japanese men with moderate body mass index. Int J Obes Relat Metab Disord 24:358-362

25. Srinivasan SR, Wang R, Chen W, Wei CY, Xu J, Berenson GS (2009) Utility of waist-to-height ratio in detecting central obesity and related adverse cardiovascular risk profile among normal weight younger adults (from the Bogalusa Heart Study). Am J Cardiol 104:721-724

26. Lin YC, Yen LL, Chen SY et al (2003) Prevalence of overweight and obesity and its associated factors: findings from National
Nutrition and Health Survey in Taiwan, 1993-1996. Prev Med 37:233-241

27. Flegal KM, Carroll MD, Ogden CL, Curtin LR (2010) Prevalence and trends in obesity among US adults, 1999-2008. Jama 303:235-241

28. Lu FH, Yang YC, Wu JS, Wu CH, Chang CJ (1998) A population-based study of the prevalence and associated factors of diabetes mellitus in southern Taiwan. Diabet Med 15:564-572

29. Hwang LC, Bai CH, Chen CJ (2006) Prevalence of obesity and metabolic syndrome in Taiwan. J Formos Med Assoc (Taiwan yi zhi) 105:626-635

30. Chobanian AV, Bakris GL, Black HR et al (2003) Seventh report of the joint national committee on prevention, detection, evaluation, and treatment of high blood pressure. Hypertension 42:1206-1252

31. Expert Committee on the Diagnosis and Classification of Diabetes Mellitus (2003) Report of the expert committee on the diagnosis and classification of diabetes mellitus. Diabetes Care 26(Suppl 1):S5-20

32. Expert Panel on Detection, Evaluation, and Treatment of High Blood Cholesterol in Adults (2001) Executive summary of the third report of the National Cholesterol Education Program (NCEP) expert panel on detection, evaluation, and treatment of high blood cholesterol in adults (adult treatment panel III). JAMA 285:2486-2497

33. Grundy SM, Brewer HB Jr, Cleeman JI, Smith SC Jr, Lenfant C (2004) Definition of metabolic syndrome: report of the national heart, lung, and blood institute/American heart association conference on scientific issues related to definition. Circulation 109:433-438

34. Ford ES, Giles WH, Dietz WH (2002) Prevalence of the metabolic syndrome among US adults: findings from the third national health and nutrition examination survey. JAMA 287:356-359

35. Misra A (2003) Revisions of cutoffs of body mass index to define overweight and obesity are needed for the Asian-ethnic groups. Int J Obes Relat Metab Disord 27:1294-1296

36. Zhou BF (2002) Predictive values of body mass index and waist circumference for risk factors of certain related diseases in Chinese adults - study on optimal cut-off points of body mass index and waist circumference in Chinese adults. Biomed Environ Sci 15:83-96

37. World Health Organization (2004) Appropriate body-mass index for Asian populations and its implications for policy and intervention strategies. Lancet 363:157-163

38. Examination Committee of Criteria for "Obesity Disease" in Japan; Japan Society for the Study of Obesity (2002) New criteria for 'obesity disease' in Japan. Circ J 66:987-992

39. Lee SY, Park HS, Kim DJ et al (2007) Appropriate waist circumference cutoff points for central obesity in Korean adults. Diabetes Res Clin Pract 75:72-80

40. Lara-Esqueda A, Aguilar-Salinas CA, Velazquez-Monroy O et al (2004) The body mass index is a less-sensitive tool for detecting cases with obesity-associated co-morbidities in short stature subjects. Int J Obes Relat Metab Disord 28:1443-1450

41. Lin CH, Chou CY, Lin CC, Huang CC, Liu CS, Lai SW (2007) Waist-to-height ratio is the best index of obesity in association with chronic kidney disease. Nutrition 23:788-793 